\title{
Preface: The modeling and simulation of complex systems
}

\author{
Christian Stummer ${ }^{1}$ (D) $\cdot$ Martin Zsifkovits $^{2} \cdot$ Karl F. Doerner $^{3}$ (D)
}

Published online: 1 September 2021

(C) The Author(s) 2021

Complex systems are a common phenomenon in real-world decision-making. The complexity of such systems arises from the numerous relationships involved and various interactions among diverse entities of the system or between a given system and its environment. As traditional analytical approaches often fall short of suitably capturing the behavior of complex systems, computer simulations come into play. These simulations provide an opportunity to alter a modeled system, observe its emergent behavior, and, thus, answer "what if" questions regarding the effectiveness of possible measures that can be applied in an attempt to achieve the decision-maker's aim.

This special section discusses recent advances in the modeling and simulation of complex systems through the following four papers, one of which is a survey paper and the other three are regular papers. It should be noted that all four papers are published under an open-access license that implies that their results can be more easily disseminated to a broader community.

The survey article by William Rand and Christian Stummer provides an overview of the strengths and criticisms of using an agent-based approach for modeling new product market diffusion. This application case is certainly a prime example of a complex system whose behavior is difficult to foresee, as it is driven by the actions and reactions of consumers, distributors, competitors, and other stakeholders, all of whom are heterogeneous in terms of their individual characteristics, attitudes, needs, and objectives. The paper provides both an introduction to the field as well as a thorough discussion of related challenges and research opportunities.

In the paper by David Schmaranzer, Roland Braune, and Karl F. Doerner, a simulationbased optimization technique for the headway optimization of complex urban mass rapid transit systems is developed. The problem is multi-objective by nature, in which trade-off solutions for costs versus service levels are calculated. As a solution technique, a twophase algorithm is developed that combines a single objective evolution strategy with a multi-directional local search. For the evaluation of the solutions within the metaheuristic search techniques, a discrete event simulation model of an urban mass rapid transit system is integrated into the optimization procedure. Further, for the evaluation of the results,

Christian Stummer

christian.stummer@uni-bielefeld.de

1 Bielefeld University, Bielefeld, Germany

2 Universität der Bundeswehr, Neubiberg, Germany

3 University of Vienna, Vienna, Austria 
realistic data pertaining to the subway network of Vienna are used as input-for example, network structure, fleet size, fluctuating demand by using hourly origin-destination matrices, and passenger distribution on waiting platforms and in vehicles. The developed solution technique outperforms the existing state-of-the-art methods.

Sabrina Backs, Hermann Jahnke, Lars Lüpke, Mareike Stücken, and Christian Stummer propose an agent-based simulation approach that can be employed to investigate the effectiveness of two supply chain strategies in an apparel market (i.e., fast fashion vs. traditional fashion) with varying product and communication strategies in several market scenarios. An apparel market constitutes a complex system, in which several competing manufacturers may utilize different supply chain strategies, while the purchasing decisions of consumers are driven by the consumers' heterogeneous preferences as well as recommendations obtained through word-of-mouth communication with their peers, normative social influence, first-hand experience, or advertising events. By contrasting the findings from the simulation experiments with results from an established analytical approach, the authors demonstrate the strengths of their approach to studying the behavior of a complex system.

In the final paper, Margaretha Gansterer, Richard Hartl, and Sarah Wieser consider an application in the sharing economy. This new form of collaborative utilization of resources is typically organized through platforms that facilitate the exchange of goods or services. The authors examine a collaborative pickup and delivery problem in which carriers can exchange requests. Pickup and delivery is a complex problem in the field of vehicle routing. In the study, the potential of collaboration under a centralized framework is analyzed. Additional constraints are included in the model to obtain fair and balanced solutions. The problem is solved with a metaheuristic search technique. Different simulation studies have revealed that centralized collaborative frameworks have the potential to generate considerable cost savings. This problem can also potentially be studied in a dynamic stochastic setting with volatile profits due to stochastic travel times. As a solution technique, a discreteevent or agent-based simulation is suggested.

Editing a special section in an issue of Annals of Operations Research would not have been possible without the most valuable inputs of numerous people. First, we would like to thank the authors for their contributions. In addition, we greatly appreciate the valuable help provided by the referees. Last but not least, we are grateful to Editor-in-Chief Endre Boros for his support as well as to Katie D'Agosta and Ann Pulido for their assistance throughout the editing process.

Funding Open Access funding enabled and organized by Projekt DEAL.

Open Access This article is licensed under a Creative Commons Attribution 4.0 International License, which permits use, sharing, adaptation, distribution and reproduction in any medium or format, as long as you give appropriate credit to the original author(s) and the source, provide a link to the Creative Commons licence, and indicate if changes were made. The images or other third party material in this article are included in the article's Creative Commons licence, unless indicated otherwise in a credit line to the material. If material is not included in the article's Creative Commons licence and your intended use is not permitted by statutory regulation or exceeds the permitted use, you will need to obtain permission directly from the copyright holder. To view a copy of this licence, visit http://creativecommons.org/licenses/by/4.0/.

Publisher's Note Springer Nature remains neutral with regard to jurisdictional claims in published maps and institutional affiliations. 